\title{
A Análise de Necessidades e sua relação com cursos e avaliação de proficiência em inglês para um grupo de pilotos militares brasileiros ${ }^{1}$
}

\author{
Ana Lígia Barbosa de Carvalho e Silva \\ Universidade Estadual de Campinas (UNICAMP), Campinas, São Paulo, Brasil \\ analigiasilva@ hotmail.com
}

DOI: http://dx.doi.org/10.21165/el.v45i2.585

\begin{abstract}
Resumo
A Análise de Necessidades, como primeiro passo no processo de elaboração de cursos, currículos e materiais para ensino de línguas, bem como para a definição do conteúdo de tarefas emavaliação de proficiência em Inglês para Fins Específicos, tem sido amplamente discutida. O objetivo deste estudo é destacar a relevância da Análise de Necessidades de línguas para um grupo de pilotos militares brasileiros. Por meio de revisão bibliográfica sobre o tema, observamos como os teóricos definem a Análise de Necessidades e traçam uma distinção conceitual entre Análise da situaçãoalvo, que compreende a língua em uso, e Análise da situação de aprendizagem, que leva em conta o modo como a língua é ensinada/aprendida. Tal distinção é fundamental para se definir qual o modelo de Análise de Necessidades mais apropriado para cada caso.
\end{abstract}

Palavras-chave: Análise de Necessidades; análise da situação-alvo; análise das necessidades de aprendizagem; inglês para fins específicos.

\section{Needs Analysis and Its Relation with Courses and Proficiency Tests in English for a Group of Brazilian Military Pilots}

\begin{abstract}
Needs Analysis has been widely discussed as the first step in the design of courses, curriculum, and materials for teaching languages, as well as in the definition of tasks for proficiency tests in English for Specific Purposes. The aim of this study is to highlight the importance of Needs Analysis for a group of Brazilian military pilots. A bibliographical review about the theme indicates how theorists define Needs Analysis and elaborate a conceptual distinction between the Target Situation Analysis, which comprises language in use, and the Learning Situation Analysis, which takes into account the way language is taught/learned. Such distinction is critical to define the most appropriate model of needs analysis to be used in each case.
\end{abstract}

Keywords: Needs Analysis; target situation analysis; learning situation analysis.

\section{Introdução}

Chama a atenção, nos dias de hoje, o crescente número de cursos de idiomas e de avaliações que parecem não cumprir o papel a que se destinam. Referimo-nos a cursos que não alcançam o objetivo de potencializar a aprendizagem e a testes ${ }^{2}$ que não avaliam, de fato, as habilidades e competências que deveriam mobilizar. Tomemos

\footnotetext{
${ }^{1}$ Este estudo é um recorte do aparato teórico que fundamenta uma dis sertação de mestrado, em andamento, com o apoio financeiro da CAPES, no Departamento de Linguística Aplicada do Instituto de Estudos da Linguagem (IEL) da Universidade Estadual de Campinas, UNICAMP.

2 Os termos "testes", "avaliação" e "exame" serão utilizados como sinônimos neste estudo.
} 
como exemplo os diversos cursos de inglês geral que hoje se oferecem, indistintamente, a grupos com necessidades específicas de aprendizagem. Da mesma forma, na área de avaliação de Inglês para Fins Específicos, consideremos os exames de proficiência destinados a fins acadêmicos que são, por vezes, aplicados em contextos de uso de inglês para fins ocupacionais.

Tal uso indiscriminado de avaliações de proficiência, assim como o emprego aleatório de cursos de inglês, tem gerado grande insatisfação por parte de examinandos e alunos. Nesse sentido, os resultados de um estudo realizado recentemente no Irã demonstram o desapontamento de alunos com um curso de Inglês para Fins Específicos que fazia parte de um programa de treinamento em aviação. Para esses alunos, o curso "não atendia a suas expectativas" porque a ele faltava "a eficiência que deveria ter" (KARIMI; SANAVI, 2014, p. 857).

Similarmente, na área de avaliação, o uso de exames para fins distintos dos quais foram concebidos pode gerar sérias consequências. Os resultados assim obtidos apresentam vulnerabilidade quanto à sua validade e, por conseguinte, podem conduzir os stakeholders $^{3}$ a decisões equivocadas. É o que ocorre quando são utilizados os resultados do TOEFL ${ }^{4}$, um exame de proficiência em inglês para fins acadêmicos, como certificação relativa a habilidades ocupacionais específicas na área de negócios, por exemplo. Nessa direção, Carr (2014, p. 6) ressalta que mais importante que pensar em tipos de testes, é preciso pensar nas decisões que neles se fundamentarão.

Quando o tema é especificamente avaliação de proficiência em língua estrangeira, é possível encontrarmos problemas quanto à escolha do melhor formato de teste a ser utilizado em cada situação. Nem sempre a melhor opção deve recair sobre o uso de testes de lápis-e-papel, ou testes de itens isolados, em inglês, discrete point tests (MCNAMARA, 1996), que avaliam conhecimento sobre a língua. Há casos em que testes de desempenho, que avaliam diretamente capacidades, por exemplo, de produção escrita ou produção oral, são mais indicados, como explica Scaramucci (2011a, p. 107):

A avaliação de desempenho pressupõe, portanto, que a melhor maneira de avaliarmos se alguém é proficiente é colocá-lo em situação em que ele possa demonstrar diretamente essa proficiência. Em outras palavras, se o que desejamos é saber se sabe escrever, a melhor maneira é solicitarmos que escreva um texto; se é capaz de interagir em situações reais, simularmos situações reais de interação e fazê-lo desempenhar-se nessas situações.

Diante da insatisfação de alunos com cursos de línguas para fins específicos, como mostra o estudo supracitado de Karimi e Savani (2014), e do uso inadequado de avaliações de proficiência, como o mencionado exemplo de utilização do TOEFL, podemos notar que tanto a eficácia ${ }^{5}$ de cursos como a validade de exames estão fortemente ligadas ao uso que deles se faz. Assim, surge a seguinte questão: que fatores

\footnotetext{
3 O termo em inglês, segundo McNamara (2000, p. 137), engloba todas as pessoas interessadas no desenvolvimento e operacionalização de um teste, como autoridades provedoras de fundos, educadores, elaboradores de testes, candidatos, instituições, entre outros.

4 TOEFL - Test of English as a Foreign Language. "O teste TOEFL@ avalia a capacidade de falantes de inglês como língua estrangeira de usar e entender a língua inglesa como ela é ouvida, falada, lida e escrita na sala de aula de uma universidade", conforme definição em site oficial do teste. Disponível em: $\langle$ http://www.ets.org/pt/toefl/ibt/faq>. Acesso em: 31 jan. 2015.

5 "Eficácia" de um curso de línguas, neste estudo, é entendida como sinônimo de "segurança de um bom resultado", ou ainda, "validez", de acordo com Houaiss (2010, p. 1102).
} 
podem contribuir para que cursos e uma avaliação de proficiência em inglês, destinados a um grupo específico de pilotos militares brasileiros, produzam seus efeitos esperados com eficácia e validade, respectivamente? Na tentativa de buscarmos respostas a tal questionamento, preliminarmente se fazem necessárias algumas considerações gerais, sob a visão de diferentes autores, quanto ao Inglês para Fins Específicos e à avaliação, ou testes, de proficiência.

O Inglês para Fins Específicos, doravante ESP, da expressão em inglês English for Specific Purposes, segundo Hutchinson e Waters (1987, p. 19), é uma abordagem para o ensino de línguas na qual as decisões, quanto ao conteúdo e ao método a serem utilizados, devem se basear nas razões que levam o aprendiz a participar do processo de aprendizagem, que podem ser para fins acadêmicos ou ocupacionais. Nesse sentido, também as proposições de Chostelidou (2011, p. 403) e Robinson (1991, p. 3-4) acentuam que um curso de ESP normalmente se direciona a um determinado objetivo, e por isso baseia-se em uma Análise de Necessidades, cuja finalidade é identificar o que exatamente os alunos devem ser capazes de fazer por meio do inglês. Também Munby (1978, p. 2) entende que a principal característica a distinguir o ESP dos cursos de inglês para fins gerais é a presença de uma Análise de Necessidades, pois é por meio dela que se pode chegar às necessidades comunicativas do aprendiz. De modo análogo, para Dudley-Evans (2010, p. 131) o ESP tem sido entendido, mais recentemente, como um movimento na área de ensino de idiomas, com metodologia, abordagem e material próprio, e que tem como característica principal o fato de fundamentar o ensino e a produção de material nos resultados de uma Análise de Necessidades.

Quanto aos testes de proficiência, Alderson (1988, p. 94) afirma que eles não avaliam conteúdo de um syllabus pré-determinado; ao contrário, "Testes de proficiência precisam criar seus próprios syllabuses, presumivelmente por meio de alguma forma de Análise da situação-alvo"6. Nesse sentido, McNamara (2000, p. 7) define testes de proficiência como aqueles que são utilizados para avaliar o uso futuro da língua. O Dictionary Language Testing, dicionário específico para a área de avaliação, desenvolvido por Davies et al. (1999, p. 154), esclarece que um teste de proficiência mede o que o examinado sabe em relação "a um propósito específico do mundo real" ". Por exemplo, se conhece a língua suficientemente para acompanhar uma palestra sobre determinado assunto, ou trabalhar como um instrutor de esqui, fazendo uso da língua. Essa visão de proficiência é compartilhada por Scaramucci (2000) que, em um artigo seminal sobre o tema, intitulado "Proficiência em LE: considerações terminológicas e conceituais", lança um olhar sobre algumas confusões terminológicas e reconhece que, em seu sentido técnico, o termo "proficiência" refere-se ao domínio e controle operacional da língua, definida de forma local e relativa, o que pressupõe o propósito de uso da língua em situação real. Nesse sentido, a referida autora sustenta que, em testes de proficiência, o instrumento de avaliação "tem suas especificações definidas com base em uma análise de necessidades do público alvo com relação ao uso futuro da língua" (SCARAMUCCI, 2000, p. 5).

Diante de tais considerações preliminares, apresentamos o pressuposto de que objetivos claramente traçados por meio de uma Análise de Necessidades são

\footnotetext{
6 "Proficiency tests need to create their own syllabuses, presumably by some form of target situation analysis".

${ }^{7}$ No original: "a specific real world purpose".
} 
fundamentais para o desenho de cursos e a elaboração de testes de proficiência em ESP. Tal pressuposto também se aplicaria a cursos e à avaliação de inglês para os pilotos militares brasileiros em questão.

\section{Objetivos para cursos e avaliações de $L 2 / L^{8}$}

A ausência de objetivos para ações em geral é uma preocupação antiga já demonstrada por filósofos como Sêneca ou Nietzsche, por meio de seus respectivos aforismos: "Nenhum vento sopra a favor de quem não sabe para onde ir" e "Muitos são os obstinados que se empenham no caminho que escolheram, poucos os que se empenham no objetivo"9. Parece até mesmo um truísmo afirmar que todo curso de línguas deveria ter um objetivo, ou que todo teste deveria ser aplicado com um propósito. No entanto, no que diz respeito à elaboração de cursos e materiais para ensino de línguas em geral, o papel indispensável de objetivos traçados por meio de uma Análise de Necessidades tem sido assim destacado:

Em resumo, uma análise de necessidades de línguas é um processo que deve ser conduzido antes da elaboração de um curso de línguas, de um syllabus, da escolha de materiais, da metodologia para ensino/aprendizagem e avaliação. Os profissionais de ESP devem ser capazes de utilizar os resultados das análises de necessidades, por eles conduzidas, para desenvolver um curso de línguas, ou um programa de treinamento, que seja adequado, prático e que obtenha êxito para um determinado contexto ${ }^{10}$. (RAHMAN, 2015, p. 26, tradução nossa).

Não obstante, é preciso considerar o aparente dilema que se instaura quanto à relação intrínseca existente entre objetivos e Análise de Necessidades. A fim de que se estabeleçam objetivos é necessária uma análise. Concomitantemente, para que uma análise tenha sucesso é necessário um objetivo a ser alcançado, o que faz com que as ações pareçam suceder-se de forma circular.

Pondo fim a tal inquietação, Chambers (1980, p. 28) sustenta que é preciso "analisar para se estabelecer necessidade", ou seja, sem que se reflita, primeirame nte, sobre o que se entende por necessidade, não haverá rumo para cursos ou avaliações. Aliás, como apontam Hutchinson e Waters (1987, p. 53-54), há sempre uma necessidade por trás de um curso, tanto de Inglês Geral como de Inglês para Fins Específicos. Todavia, o que caracteriza o ESP não são essas necessidades específicas, mas sim a consciência que se tem delas. Portanto, é fundamental que se conheça o que, especificamente, se pretende alcançar por meio de um curso, ou o que se pretende avaliar por meio de um teste de proficiência, de modo a viabilizar o desenho de cursos eficazes e avaliações de proficiência válidas em L2/LE.

\footnotetext{
${ }^{8}$ Neste estudo não consideramos as questões conceituais entre os termos "s egunda língua (L2)" e "língua estrangeira (LE)".

${ }^{9}$ Citações disponíveis em:

$<$ http://pensador.uol.com.br/busca.php?q=Muitos+s\%C3\%A3o+os+obstinados+que+se+empenham+no+ caminho+que+escolheram\%2C+poucos+os+que+se+empenham+no+obj>. Acesso em: 01 fev.2015.

10 No original: "In summary, a language needs analysis is a process that must be conducted prior to a language course and syllabus design, materials selection, teaching and learning methodology and evaluation. The ESP practitioners should be able to utilize the results of needs analysis research which he or she conducts to develop a language course or training program that is suitable, practical and successful for a particular context."
} 
Quanto a cursos de Inglês para Fins Específicos, Hutchinson e Waters (1987, p. 12) afirmam que é preciso tornar o aprendiz capaz de "funcionar adequadamente na situação-alvo". Assim sendo, é necessário que se determine com precisão o que compõe essa situação-alvo, para, posteriormente, dar seguimento a uma análise dos traços linguísticos de tal situação.

No que se refere a avaliações, Bachman (1990, p. 78) destaca que o aspecto mais importante no desenvolvimento e no uso de testes de línguas é o propósito, ou os propósitos para os quais ele é pensado. Douglas (2000, p. 20), por sua vez, destaca que o primeiro passo rumo à definição de um objetivo para avaliações com fins específicos deve ser a descrição do contexto e das tarefas que se pretende realizar na situação-alvo, por meio de uma Análise de Necessidades.

\section{Análise de Necessidades: conceito e metodologia}

Após uma revisão da literatura, a partir do termo em inglês "Needs Analysis" em sites de busca na internet e em bibliotecas, foram encontradas várias definições e diversos procedimentos recomendados para sua realização. Historicamente, o termo "Análise de Necessidades", de acordo com West (1994; 1997), surgiu na Índia, no início dos anos 20, em um contexto de necessidades de alunos em uma escola secundária. Por meio de uma análise, buscava-se investigar o que os aprendizes deveriam fazer com a língua estrangeira na situação-alvo, e como os aprendizes poderiam aprendê-la.

Por 50 anos o termo permaneceu latente, tendo em vista que o ensino se apoiava fundamentalmente na análise informal e um tanto quanto intuitiva que professores faziam das necessidades de seus alunos. No início dos anos 70, o conceito de uma análise mais formal ressurgiu devido ao crescente interesse pelo Inglês para Fins Específicos, ESP, emergente nas contingências de uma época em que as comunicações e a tecnologia expandiam-se em ritmo acelerado. A Análise de Necessidades, como processo formal de investigação, ganhou mesmo forças com o modelo proposto por John Munby, em 1978, em sua obra Communicative Syllabus Design, que se tornou referência nas pesquisas sobre elaboração de cursos na área de ESP.

No início dos anos 80, a Análise de Necessidades, fortemente associada a contextos de ensino/aprendizagem, voltou-se para a elaboração de currículos, desenho de cursos, métodos, materiais e estudos sobre estratégias e estilos de aprendizagem. No final dos anos 90, a dupla Dudley-Evans e St. John (1998, p. 125) propôs um conceito de Análise de Necessidades que, além de considerar a situação-alvo e a situação de aprendizagem, levava em conta também o nível de aprendizagem do interessado antes de iniciar um curso. Por essa perspectiva, tornou-se possível determinar o ponto de partida, onde o aprendiz se encontra inicialmente no processo de aprendizagem, o ponto de chegada, que é a situação-alvo onde se pretende chegar, e também os meios para se chegar até lá.

Atualmente, a literatura na área de ESP nos mostra que a Análise de Necessidades é um processo com características variadas e peculiares que pode servir a diferentes propósitos. Pode variar quanto a seu foco de uso, conforme Brown (2009, p. 273-274), pode ser utilizada em larga escala, como a realizada por Thomson (2015, p. 18-40) junto a militares australianos, ou localmente, em situações de sala de aula, como aquela realizada por professores ao planejarem seus cursos. Seu alcance é variável: internacio nal, 
nacional, estatal, de acordo com distritos educacionais, em programas ou salas de aula, ou pode ainda versar sobre necessidades de Inglês para Fins Específicos (ESP), tanto no âmbito ocupacional como acadêmico. Em resumo, observa-se que a Análise de Necessidades traz as marcas de um recurso contínuo, amplo e multifacetado (FLOWERDEW, 2013, p. 325), por meio do qual as necessidades dos aprendizes ou examinandos podem ser conhecidas, categorizadas e avaliadas.

Quanto a aspectos metodológicos da Análise de Necessidades, Long (2005, p. 10) elenca os seguintes procedimentos como úteis e recomendáveis: consulta à literatura específica; conversas com aprendizes, professores, linguistas aplicados e especialistas na área investigada; triangulação de dados. Para o mesmo autor, tanto métodos indutivos como dedutivos podem ser utilizados, tais como intuições de especialistas na área, observação participante e não participante, entrevistas estruturadas ou não-estruturadas e questionários. Long ressalta que as entrevistas não-estruturadas são especialmente recomendadas quando o entrevistador/pesquisador não tem grande conhecimento sobre o conteúdo específico do assunto pesquisado, podendo, assim, utilizar-se desse procedimento para que o respondente o auxilie.

Procedimentos metodológicos semelhantes também são sugeridos por Hutchinson e Waters (1987), Jasso-Aguilar (1999), Dörnyei (2007), Brown (2009) e, mais recentemente, Serafini, Lake e Long (2015), que enfatizam a necessidade de uso diversificado de métodos para a obtenção e triangulação de dados, a fim de proporcionar maior validade à Análise de Necessidades.

\section{Análise de Necessidades: conteúdo}

Apesar de parecer demasiadamente simplificado afirmar que o principal motivo para se realizar uma Análise de Necessidades é conhecer as necessidades de alguém em relação a algo, complexo mesmo é saber em que tais necessidades consistem de fato. Há que se indagar: necessidades de quem; em que contexto; para que finalidade?

No que tange às necessidades, Hutchinson e Waters (1987, p. 58-59) fazem uma distinção entre "necessidades-alvo", que correspondem a tudo que o aprendiz deve ser capaz de realizar na situação-alvo, e "necessidades de aprendizagem", que se referem a tudo que o aprendiz necessita fazer durante o processo de aprendizagem, a fim de aprender.

As necessidades-alvo, conforme os mesmos autores, são subdivididas em três categorias: necessidades, lacunas e desejos ${ }^{11}$. Por "necessidades", ou necessities, entendese tudo aquilo que o aprendiz precisa saber para funcionar, ou desempenhar-se, na situação-alvo; o termo "lacunas" é utilizado para designar a diferença entre aquilo que o aprendiz já sabe e aquilo que ainda the falta. É a distância entre a proficiência que o aprendiz já traz consigo e a proficiência almejada; "desejos" são as expectativas, ou seja, tudo aquilo que o aprendiz subjetivamente espera alcançar. São representações ligadas àquilo que os aprendizes querem realizar por meio da língua-alvo ${ }^{12}$, independentemente do que os responsáveis pelo curso, ou o professor, afirmem ser necessário.

\footnotetext{
11 "Necessities", "lacks" e "wants".

12 Por questão de praticidade, utilizaremos neste estudo o termo "língua-alvo" para designar "a língua que se almeja aprender”, conforme Paiva (2014, p. 177), a despeito de críticas, apontadas pela própria autora, no sentido de que a metáfora do alvo pode ter uma conotação que remeta a algo fixo e imóvel a ser atingido.
} 
Já as necessidades de aprendizagem estão ligadas a fatores inerentes ao processo de aprendizagem em si, como o local, a frequência, o conteúdo, os participantes e os estilos de aprendizagem de cada um, conforme Hutchinson e Waters (1987, p. 60-63). Esses autores sugerem algumas perguntas para nortear a análise das necessidades de aprendizagem. São elas: Por que os aprendizes estão fazendo o curso de ESP? Como eles aprendem? Que recursos estão disponíveis? Quem são os aprendizes? Onde e quando o curso de ESP ocorrerá?

Chambers (1980, p. 25-26), em um detalhado estudo sobre a ambiguidade e imprecisão do termo "Análise de Necessidades" na "pletora de terminologia" (p. 25) provocada pelos estudiosos da área, reconhece que ambos os termos, "análise" e "necessidades", suscitam esclarecimentos. O autor apresenta dois exemplos para ilustrar os diferentes significados de "necessidades". No primeiro exemplo, "O homem necessita de água para viver", o sentido em português encaixa-se em "ter necessidades" ou "precisar de algo", que muito se assemelha às necessidades, ou necessities, conforme Hutchinson e Waters (1987). No segundo, "O que necessito são longas férias em um lugar com sol", o sentido do termo corresponde a "desejar" ou "ansiar por", que traz semelhança com o conceito de desejos, ou wants, proposto por esses mesmos autores. No tocante ao termo "análise", Chambers (1980, p. 28) adverte que ele não deve se restringir à coleta de informações, mas deve pressupor também a categorização e a avaliação dos dados.

Vian Jr. (2008, p. 146) destaca que a Análise de Necessidades deve ter um caráter contínuo, e não deve ser vista como um produto estanque, determinante de todo o processo de ensino-aprendizagem. No mesmo sentido, autores como Robinson (1991, p. 15), Hutchinson e Waters (1987, p. 59) e Dudley-Evans e St. John (1998, p. 121) reforçam a importância da continuidade no desenvolvimento de um curso de ESP, conferindo à Análise de Necessidades um aspecto cíclico. Entendendo-se que as necessidades mudam, a análise não pode ser única e isolada.

\section{Análise da situação-alvo e Análise da situação de aprendizagem}

A partir das considerações aqui realizadas sobre o que se entende por "necessidades", observamos que não há consenso entre os estudiosos da área de ESP sobre o que, de fato, deva ser o conteúdo de uma Análise de Necessidades.

Para Chambers (1980), o conteúdo da Análise de Necessidades deve estar centrado na Análise da situação-alvo, Target Situation Analysis (TSA), que é o processo de observação, investigação, descrição e categorização das atividades que compreendem a língua em uso. Segundo esse mesmo autor, a TSA corresponde ao "[...] estabelecimento das necessidades comunicativas e suas realizações, resultante de uma análise de comunicação na situação-alvo"13. (CHAMBERS, 1980, p. 29). Por essa perspectiva, a análise não se esgota nas necessidades dos alunos apenas, mas estende-se às necessidades de todos os participantes e interessados na elaboração de um curso. Trata-se, portanto, de um processo específico baseado na descrição objetiva da situação-alvo, e que tem por finalidade conhecer aquilo que Scaramucci $(2000,2011 b)$ aponta como essencial para o

\footnotetext{
${ }^{13}$ No original: "[...] the establishment of communicative needs and their realizations, resulting from an analysis of the communicative needs and their realizations, resulting from an analys is of the communication in the target situation."
} 
conceito de proficiência: é preciso saber "em que e para que" alguém deve ser proficiente em um dado contexto.

Esse parece ser também o pensamento de Munby (1978, p. 24), para quem a Análise de Necessidades deve voltar-se para a situação-alvo, para o aluno e para o contexto em que ele está inserido. Seu modelo de Análise de Necessidades, considerado um marco na história do ESP, estabelece um perfil de necessidades de comunicação que leva em conta o contexto sociolinguístico de uso da língua, seguindo a concepção de competência comunicativa defendida por Dell Hymes (1971). De acordo com tal modelo, antes mesmo de se decidir o que ensinar ao aprendiz, é preciso conhecer suas "necessidades comunicativas", ou seja, seu modo de comunicação, suas atividades e seus interlocutores.

Nesse sentido, para Dudley-Evans e St. John (1998, p. 126), uma Análise de Necessidades deve ter por finalidade, primeiramente, conhecer o aprendiz como pessoa, para em seguida conhecê-lo também como aprendiz e usuário da língua. Deve, ainda, procurar compreender melhor como a aprendizagem de línguas pode ser maximizada para um determinado grupo, além de buscar conhecer as situações-alvo e o ambiente de aprendizagem. Em outra publicação, Dudley-Evans (2010, p. 133) afirma que, uma vez realizada uma análise preliminar de cunho objetivo e descritivo, pode-se iniciar outra investigação mais detalhada e subjetiva, caracterizada pela busca de informações sobre os aprendizes, propriamente ditos, da língua estrangeira, seu nível de proficiência, suas dificuldades de aprendizagem, as habilidades que lhes faltam (chamadas "lacunas") e suas percepções sobre o que precisam e desejam aprender. A essa segunda etapa da Análise de Necessidades o autor dá o nome de Análise da situação de aprendizagem.

Hutchinson e Waters (1987, p. 58-63) também propuseram seus modelos de Análise de Necessidades, pautados pela distinção entre Análise da situação-alvo e a Análise das necessidades de aprendizagem. Os autores comparam a primeira análise a uma viagem, em que é preciso conhecer o ponto de partida (lacunas), o ponto de chegada (necessidades) e as diversas visões do destino onde se pretende chegar (desejos). Já a segunda seria a rota a ser seguida, ou seja, o caminho a trilhar desde o ponto de partida até o destino. Tais ensinamentos podem ser assim resumidos: "Se, por um lado, a análise da situação-alvo nos aponta para o que o aprendiz precisa saber /aprender, a análise de aprendizagem tenta descobrir como ele poderá aprender" (GALLO, 2006, p. 24, grifo do autor). Ambos os modelos de Análise de Necessidades foram sintetizados e representados por Vian Jr. (2008, p. 145) em um quadro que transcrevemos abaixo: 
Quadro 1: Comparação entre os modelos de análise de necessidades, da situação-alvo e da situação de aprendizagem, segundo Vian $\mathrm{Jr}(2008$, p. 145).

\begin{tabular}{|l|l|c|}
\hline & Modelo para análise da situação-alvo & $\begin{array}{c}\text { Modelo para análise das necessidades de } \\
\text { aprendizagem }\end{array}$ \\
\hline Por que & Por que a língua é necessária? & Por que os aprendizes fazem o curso? \\
\hline Como & Como a língua será usada? & Como os aprendizes aprendem? \\
\hline Qual & Quais serão as áreas de conteúdo? & Quais as fontes disponíveis? \\
\hline Quem & Com quem o aprendiz vai usara língua? & Quem são os aprendizes? \\
\hline Onde & Onde a língua será usada? & Onde o curso será ministrado? \\
\hline Quando & Quando a língua será usada? & Quando o curso acontecerá? \\
\hline
\end{tabular}

Essa divisão entre o modelo para a Análise da situação-alvo e o modelo para a Análise das necessidades de aprendizagem, baseada em perguntas propostas por Hutchinson e Waters (1987, p. 59-63), é fundamental para entendermos "o que" deve ser alvo de análise em cada caso concreto. É possível observar, a partir do quadro proposto por Vian Jr. (2008), que determinadas perguntas são necessárias no contexto em que se busca tão somente conhecer a situação-alvo, por exemplo, para a elaboração de tarefas para testes de desempenho; outras perguntas, no entanto, devem ser feitas quando se busca conhecer a situação de aprendizagem, por exemplo, durante a elaboração de um currículo, de um curso de línguas, de material didático ou na formação de professores de ESP.

Todavia, cabe ressalvar que para a área de avaliação, especificamente, os dois modelos propostos por Hutchinson e Waters (1987) podem ser úteis, a depender do tipo de avaliação que se pretende elaborar. Se o que se busca é a elaboração de um teste de rendimento ou uma avalição diagnóstica - o que pressupõe um curso em andamento - o modelo para Análise da situação-alvo não basta. Faz-se necessário também o emprego do modelo para a Análise das necessidades de aprendizagem, a fim de se identificar como os alunos aprendem. Entretanto, para a elaboração de um teste de proficiência de L2/LE, por meio do qual se pretende avaliar as habilidades que o examinando possui, independentemente de um curso ou currículo pré-determinado, necessário se faz, tão somente, o uso do modelo para a Análise da situação-alvo, sendo irrelevante indagar-se, nesse caso, sobre o modo como a aquisição da língua ocorreu.

Dessa forma, é possível afirmar que a realização de uma Análise de Necessidades pressupõe, antes de mais nada, a delimitação daquilo que intencionamos realizar por meio dela. Se o que tivermos como meta for a definição de um construto para um exame de proficiência específico, ou ainda, se o que buscamos é o processo de validação de um teste de proficiência já existente, bastará realizar a Análise da situação-alvo, ou da Target Language Use (TLU), conforme Douglas (2000). Será, então, preciso investigar por que a língua se faz necessária; como a língua será usada; quais serão as áreas de conteúdo necessárias; quem serão os interlocutores; onde, por quais meios e quando a língua será usada, ou ainda, qual a frequência de exposição à língua. Mais que saber "como" o aprendiz chegou até o nível de proficiência em que se encontra, será preciso conhecer em quais situações se dará o uso futuro da língua.

Por outro lado, se o que almejamos é a elaboração de um curso, syllabus, material didático, ou a formação e o treinamento de professores, os dois modelos de análises serão necessários. Será preciso ir além da Análise da situação-alvo - aquela que determina o objetivo a ser alcançado - e prosseguir rumo à análise das necessidades de aprendiza ge m, procurando conhecer em profundidade as razões que levam o aprendiz a buscar um curso de ESP, seu histórico de aprendizagem, suas preferências e atitudes em relação à língua 
a ser aprendida. Fundamental será também investigar quais as abordagens de ensino e estratégias de aprendizagem mais adequadas, quais os meios e recursos disponíveis, tais como o local, o horário e a frequência do curso, dentre outros aspectos diretamente ligados ao processo de ensino/aprendizagem.

Percebe-se, assim, que a Análise de Necessidades poderá apresentar um conteúdo diferente, a depender do fim para o qual se destina. Sabendo-se claramente o que se busca conhecer por meio dela, é possível tornar sua realização mais ágil, precisa e viável. Em nosso estudo, como veremos a seguir, optamos pela realização da Análise da situação alvo.

\section{A Análise de Necessidades para um grupo de pilotos militares brasileiros}

Este artigo é um recorte do aparato teórico que fundamenta uma dissertação de mestrado em andamento no Instituto de Estudos da Linguagem (IEL), UNICAMP, por meio da qual se busca investigar as necessidades de uso da língua inglesa por um grupo de pilotos militares, da Força Aérea Brasileira (FAB), que tem por missão oficial realizar demonstrações aéreas a fim de representar o Brasil e a FAB no Brasil e no exterior. Esses pilotos pertencem ao Esquadrão de Demonstração Aérea (EDA), grupo que é mais popularmente conhecido como "Esquadrilha da Fumaça".

Um estudo anterior, que trata da proficiência em línguas estrangeiras para militares norte-americanos, indicou que "os requisitos para a proficiência na língua associados a determinada atividade militar devem ser conhecidos, pois o desempenho satisfatório de tal atividade pode vir a ser uma questão de vida ou morte"14. (LETT, 2005, p. 105). Aliás, em todo o mundo cresce o interesse específico por Análises de Necessidades de línguas no contexto militar, como se pode notar por meio de recentes publicações (BIASE; GRATTON, 2010; KUSHI, 2013; PARK, 2015; QADDOMI, 2013; SOLAK, 2013; THOMSON, 2015).

Por mais de 10 anos, tivemos a oportunidade de trabalhar como professora de inglês de membros do EDA, em aulas individuais e em pequenos grupos, o que motivou a realização da pesquisa que originou este artigo. Durante esse período, percebeu-se que os integrantes da equipe, de um modo geral, não tinham definido de forma clara "em que" ou "para que" queriam/precisavam ser proficientes em inglês. Diante de tal inquietação, decidimos realizar uma Análise de Necessidades para conhecer as características da atividade ocupacional dos Oficiais Aviadores do EDA, bem como as necessidades de uso da língua inglesa para o desempenho de suas atividades ocupacionais.

É preciso esclarecer, portanto, que a referida dissertação de mestrado visa realizar uma Análise da situação-alvo (TSA), conforme defendida por Chambers (1980), explicitada por Hutchinson e Waters (1987) e mencionada também por Vian Jr. (2008). A metodologia utilizada compreende a descrição dos membros do EDA, de suas atividades e funções ocupacionais e das atividades e tarefas que exigem o uso de inglês pelo grupo no desempenho de suas diversas atribuições. Buscamos conhecer quais são as macro-habilidades linguísticas mais necessárias e desejadas pelo grupo (compreensão oral, produção oral, compreensão escrita, e produção escrita) e quais as situações, em voo e em solo, em que a língua se faz necessária.

${ }^{14}$ No original: "[...] the language proficiency requirements associated with a given military job must be known, because satisfactory job performance may well be a life or death matter." 
No momento, o estudo encontra-se em fase de descrição - por meio de uma job analysis (PRINCE, 1984, p. 110), ou análise do trabalho (MCNAMARA, 1996, p. 95) das atividades ocupacionais, das funções e tarefas realizadas pelo EDA. É nosso intento delinear, por meio de uma Análise da situação-alvo (CHAMBERS, 1980), as situações aproximadas de uso da língua, com o propósito de conhecer "em que" e "para que", segundo Scaramucci (2000), a proficiência em inglês se faz necessária à equipe. Dentro do contínuo de especificidades para o ESP proposto por Douglas (2000, p. 1), procuramos entender quão específico deve ser o uso de inglês pelo grupo.

Também investigamos como é o processo de ensino/aprendizagem nas disciplinas Língua Inglesa (Inglês Geral) e Inglês Técnico para Aviação (Inglês para Fins Específicos) na Academia da Força Aérea (AFA), onde os pilotos do EDA recebem formação acadêmica, militar e operacional. Isso nos levou a conhecer "o ponto de partida", segundo Hutchinson e Waters (1987), onde os pilotos se encontram na situação atual, a fim identificarmos eventuais lacunas (lacks) entre o que eles já sabem, e são capazes de desempenhar, e o nível necessário/desejado (needs/wants) de proficiência em inglês para o desempenho de suas atividades.

Os dados gerados por meio de grupos focais, entrevistas, observações e análise de documentos devem ser categorizados, triangulados e interpretados sob a luz do quadro teórico pertinente, a fim de melhor conhecermos as características do EDA e as necessidades de seus Oficiais Aviadores em relação ao uso da língua inglesa. Tendo em vista que o referido estudo ainda está em andamento, não há resultados que possam ser relatados neste artigo. Esperamos que a Análise de Necessidades assim realizada sirva de subsídio para o desenho de cursos eficazes e avaliações de proficiência válidas em inglês como L2/LE para o grupo mencionado, sempre de acordo com a dinâmica e as idiossincrasias que caracterizam o Inglês para Fins Específicos.

\section{Considerações finais}

Neste estudo, discorremos sobre aspectos teóricos da Análise de Necessidades, aqui tomada em toda a sua dimensão, alcance e complexidade, como um processo contínuo, multifacetado e variável em relação à sua escala ou foco de uso. Retomando a questão inicial que motivou esta nossa reflexão, entendemos, por todo o aqui exposto, que uma Análise de Necessidades apropriada é um procedimento determinante para que cursos e avaliações de inglês produzam seus efeitos esperados, com eficácia e validade.

As considerações que ora apresentamos poderão ser úteis a novos estudos com outros grupos, militares ou não, com características e necessidades semelhantes. Em cada caso, será preciso considerar: se o que buscamos é a definição de um construto ou a validação de um exame de proficiência em L2/LE, a Análise da situação-alvo será sempre mandatória; no entanto, se o que almejamos é o desenho de um curso, a elaboração de um syllabus, de material didático e a formação específica de professores de L2/LE, será preciso ir além, pois tanto a Análise da situação-alvo como a Análise da situação de aprendizagem serão necessárias. 


\section{REFERÊNCIAS}

ALDERSON, J. C. Testing and its Administration in ESP. In: CHAMBERLAIN, D.; BAUMGARDNER, R. J. (Ed.). ESP in the Classroom: Practice and Evaluation. Oxford: Modern English Publications in association with The British Council, 1988. p. 87-97.

BACHMAN, L. F. Fundamental Considerations in Language Testing. Oxford: Oxford University Press, 1990. 408 p.

BIASE, M. J.; GRATTON, F. Interpreting the Speaking Performance Requirements of Forward Air Controllers. In: JOYCE, H. de S.; THOMSON, E. A. (Ed.). Language in Uniform. United Kingdom: Cambridge Scholars Publishing, 2015. p. 2-17.

BROWN, J. D. Foreign and Second Language Needs Analysis. In: LONG, M. H., DOUGHTY, C. J. (Ed.). The Handbook of Language Teaching. United Kingdom: Blackwell, 2009. Cap. 16, p. 269-293.

CARR, N. T. What are we testing and why? In: Designing and Analyzing Language Tests. Oxford: Oxford University Press, 2014. Cap. 1, p. 5-23.

CHAMBERS, F. A Re-evaluation of needs analysis in ESP. The ESP Journal, [s.1.], v.1, n.1, p. 25-33, 1980. Disponível em: <http $/ /$ ac.els-cdn.com/0272238080900074/1-s2.00272238080900074-main.pdf?_tid=ff728812-11ef-11e6-8239-

00000aacb35f\&acdnat=1462363496_1ffe96e032a74fe7da504>. Acesso em: 3 mai. 2016.

CHOSTELIDOU, D. Needs-based course design: the impact of general English knowledge on the effectiveness of an ESP teaching intervention. Procedia Social and Behavioral Sciences, Greece. n.15, p. 403-409, 2011. Disponível em: <http:/ac.elscdn.com/S1877042811002916/1-s2.0-S1877042811002916-main.pdf?_tid=fba09a22-

11fd-11e6-8aaa-

00000aacb360\&acdnat=1462369502_3328e0571757da275467cf10bf40af10>. Acesso em: 3 mai. 2016.

DAVIES, A. et al. Dictionary of Language Testing. In: MILANOVIC, M. (Ed.). Studies in Language Testing, v. 7. Cambridge: UCLES - Cambridge University Press, 1999. 272 p.

DOUGLAS, D. Assessing Languages for Specific Purposes. Cambridge: Cambridge University Press, 2000. 311 p.

DÖRNYEI, Z. Research methods in applied linguistics. Oxford: Oxford University Press, 2007. 336 p.

DUDLEY-EVANS, T.; ST JOHN, M. J. Developments in English for Specific Purposes. Cambridge University Press, 1998. 298 p.

DUDLEY-EVANS, T. English for Specific Purposes. In: CARTER, R.; NUNAN, D. (Ed.). The Cambridge Guide to Teaching English to speakers of Other Languages. Cambridge: Cambridge University Press, 2010. Cap. 19, p. 131-136. Disponível em: <http//dx.doi.org/10.1017/CBO9780511667206..02>. Acesso em: 23 jan. 2015.

FLOWERDEW, L. Needs Analysis and Curriculum Development in ESP. In: PALTRIDGE, B.; STARFIELD, S. (Ed.). The Handbook of English for Specific Purpose. West Sussex: John Wiley \& Sons, 2013. Cap. 17, p. 325-346. 
GALLO, C. Inglês para pilotos: análise das necessidades das situações-alvo. 2006. 130 f. Dissertação (Mestrado em Linguística Aplicada e Estudos da Linguagem) - Pontifícia Universidade Católica, São Paulo.

HOUAISS, A.; VILlAR, M. S. Dicionário Houaiss da Língua Poruguesa. Rio de Janeiro: Objetiva, 2001. 2922 p.

HUTCHINSON, T.; WATERS, A. English for Specific Purposes: A learning-centered approach. Cambridge: Cambridge University Press, 1987. 183 p.

JASSO-AGUILAR, R. Sources, Methods and Triangulation in Needs Analysis: A critical perspective in a case study of Waikiki hotel maids. English for Specific Purposes, Great Britain, v.18, n.1, p. 27-46, 1999. Disponível em: $<\mathrm{http} / /$ www.sciencedirect.com/science/article/pii/S0889490697000483>. Acesso em: 3 mai. 2016.

KARIMI, P.; SAVANI, R. V. Analyzing English Language Learning Needs among Students in Aviation Training Program. Procedia - Social and Behavioral Sciences, Tehran, Iran, n.98, p. 852-858, 2014. Disponível em: 〈www.sciencedirect.com〉. Acesso em: 25 jan. 2015.

KUSHI, Q. Language Skills of PMA Cadets: Insights into Perceptions of Instructors. Pakistaniaat: A 80 journal of Pakistan Studies, Paquistão, v.4, n.3, p. 175-188, 2012. Disponível em: $<$ http//www.scholarlyexchange.org/ojs/index.php/PKN/article/viewFile/10370/7729>. Acesso em: 3 fev. 2016.

LETT, J. A. Foreign language needs assessment in the US military. In: LONG, M. H. (Ed.). Second Language Needs Analysis. New York: Cambridge University Press, 2005. Cap. 3, p. 105-126.

LONG, M. H. Methodological issues in learner needs analysis. In: LONG, M. H. (Ed.). Second Language Needs Analysis. New York: Cambridge University Press, 2005. Cap. 1, p. 19-78.

MCNAMARA, T. Measuring Second Language Performance. England: Addison Wesley Longman Limited, 1996. 323 p.

Language Testing. Oxford: Oxford University Press, 2000. 140 p.

MUNBY, J. Communicative Syllabus Design. Cambridge: Cambridge University Press, 1978. $232 \mathrm{p}$.

PAIVA, V. L. M. O. Aquisição de Segunda Língua. São Paulo: Parábola, 2014. 198 p.

PARK, K. A Needs Analysis of English for Korean Naval Officers. 2015. $101 \mathrm{f}$. Thesis (Master of Arts in Teaching of English as a Second Language). Graduate College of the University of Illinois at Urbana-Champaign, Urbana, Illinois, 2015. Disponível em: $<$ https://www.ideals.illinois.edu/bitstream/handle/2142/78565/PARK-THESIS-

2015.pdf?sequence=1>. Acesso em: 27 out. 2015.

PRINCE, D. Workplace English: approach and analysis. In: The ESP Journal. USA, v.3, n.2, p. 109-116, 1984.

QADDOMI, H. A. English for Specific Purposes in Palestinian context: Determining EFL cadets' needs at Al Istiqlal University. Theory and Practice In Language Studies, 
Palestina, v.3, n.7, p. 1110-1122, 2013. Disponível em: $<$ http $/ /$ ois.academypublisher.com/index.php/tpls/article/viewFile/tpls030711101122/72 61>. Acesso em: 3 fev. 2016.

RAHMAN, M. English for Specific Purposes (ESP): A Holistic Review. Universal Journal Of Educational Research, Bangladesh, v.1, n.3, p. 24-31, 2015. DOI: 10.13189/ujer.2015.030104 Disponível em: <http//www.hrpub.org/journals/article_info.php?aid=2200>. Acesso em: 6 jan. 2016.

ROBINSON, P. ESP Today: A Practitioner's Guide. Hemel Hempstead: Prentice Hall International, 1991. $146 \mathrm{p}$.

SCARAMUCCI, M. V. R. Proficiência em LE: Considerações terminológicas e conceituais. Trabalhos em Linguística Aplicada, Campinas, v.36, p. 11-22, jul./dez. 2000. Disponível em: <http://revistas.iel.unicamp.br/index.php/tla/article/view/2500/4665> . Acesso em: 4 out. 2015.

Validade e consequências sociais das avaliações em contextos de ensino de línguas. LINGVARVMARENA, v.2, p. 103-120, 2011a. Disponível em: <http//ler.letras.up.pt/uploads/ficheiros/9836.pdf>. Acesso em: 7 nov. 2015.

O Exame de proficiência em língua inglesa para controladores de voo do SISICEAB - uma entrevista com Matilde Scaramucci. In: Aviation in focus (Porto Alegre), v.2, n.1, p. 3-12 - jan./jul. 2011 b.

SERAFINI, E. J.; LAKE, J. B.; LONG, M. H. Needs analysis for specialized learner populations: Essential methodological improvements. English for Specific Purposes, USA, v.40, p. 11-26, out. 2015. DOI: 10.1016/j.esp.2015.05.002. Disponível em: <http//api.else vier.com/content/article/PII:S088949061500037X?httpAccept=text/xml> . Acesso em: 17 ago. 2015.

SOLAK, E. A study of needs analysis at Turkish Gendarmerie in terms of English for Specific Purposes. The Journal Of Language And Linguistic Studies, Turquia, v.2, n.8, p. 48-63, 2012. Disponível em: <http//www.jlls.org/index.php/jlls/article/view/130/130>. Acesso em: 3 fev. 2016.

THOMSON, E. A. Language at the Pointy End: Understanding the Additional Language Needs of the Australian Defence Force. In: JOYCE, H. S.; THOMSON, E. A. Language in Uniform: Language Analysis and Training for Defence and Policing Purposes. UK: Cambridge Scholars Publishing, 2015. Cap. 2, p. 18-40.

VIAN JUNIOR, O. A Análise de Necessidades no Ensino de Inglês em Contextos Profissionais. The ESPecialist, São Paulo, v.29, n. 2, p. 137-158, 2008.

WEST, R. Needs Analysis in Language Teaching. Language Teaching, UK, v.27, p. 119, 1994.

Needs analysis: State of the Art. In: HOWARD, R.; BROWN, G. Teacher Education for LSP. UK: Multilingual Matters Ltd., 1997. Cap. 5, p. 68-79.

Recebido em: 08/09/2015

Aprovado em: 29/02/2016 